\title{
O menino e o mundo (2013) de Alê Abreu: campo-cidade, estilo indireto livre e 0 direito à cidade
}

Fábio Raddi Uchôa

\section{Resumo}

0 objetivo é analisar a animação $O$ menino $e 0$ mundo (2013), de Alê Abreu, levando-se em conta aspectos temáticos, narrativos e interpretativos. Trata-se, respectivamente, de: a) questionar as particularidades quanto à representação do campo e da cidade (BERNARDET, 1980); b) identificar uma estrutura narrativa com momentos lúdicos, de eclosão do estilo indireto livre (PASOLINI, 1989), em que os regimes de enunciação sofrem modificações; c) examinar o gesto artístico de $O$ menino e o mundo, com seus vestígios de utopia transformadora, não sem ambiguidades, inserindo-0 entre outros discursos que retomam o direito à cidade (HARVEY, 2013; LEFEBVRE, 1999), sob os ecos das jornadas de 2013.

\section{Palavras-Chave}

Cinema de animação. 0 campo e a cidade. Discurso indireto livre.

\section{Fábio Raddi Uchôa}

Doutor em Ciências da Comunicação pela Universidade de São Paulo - USP. Professor Adjunto da Universidade Tuiuti do Paraná, Curitiba, Paraná, Brasil. E-mail: raddiuchoa@gmail.com

\section{Introdução}

0 filme $O$ menino e o mundo (2013), de Alê Abreu, é um dos marcos do recente cinema brasileiro de animação, tendo conquistando diversos prêmios internacionais ${ }^{1}$ e a indicação para concorrer ao 0scar de sua categoria em 2016. ${ }^{2}$ Realizado com investimento de menos de dois milhões de reais, sua ideia inicial originou-se durante a criação de um documentário com animações chamado Canto Latino, que lançaria um olhar sobre a cultura latino-americana com 0 apoio de músicas de protesto. 0 trabalho do diretor, no mínimo desde 2008, propõe uma união entre o imaginário infantil e a inserção de passagens musicais, que se consolidará com 0 excelente desempenho e inventividade em 0 menino e o mundo. Tal tendência já se apresentava em Garoto Cósmico (2008) que se inspira no universo circense, na ficção científica e em possíveis contatos com a grafia psicodélica de Yellow Submarine dos Beatles (George Dunning, 1968), incluindo passagens nas quais o fluxo da montagem acelera e a música ganha relevância. 
O menino e o mundo, por sua vez, será em parte permeado por aquarelas, colagens e tracejados infantis, que se afirmam como cerne de uma proposta particular: uma enunciação contaminada pelo ponto de vista da criança, desdobrando-se num modo particular de estilo indireto livre. Trata-se de uma diegese especialmente marcada por rupturas lúdicas, na qual a música e as oposições entre campo e cidade assumem relevância narrativa, reverberando a experiência do protagonista. A partir de um viés que une interpretação e análise interna, o trajeto aqui se dividirá em três passos inter-relacionados: a) a definição das configurações do confronto campo-cidade ao longo do filme; b) o exame as presenças do estilo indireto livre numa estrutura narrativa com influências do gênero musical; e c) a interpretação de tais traços, inserindo-se O menino e o mundo entre outros discursos que, coincidentemente, retomam a noção de direito à cidade, no contexto dos eventos de junho de 2013. A partir de uma abordagem bastante experimental, busca-se lançar luz a uma obra cuja potência narrativa, até 0 momento, foi praticamente esquecida pela pesquisa acadêmica e a crítica especializada.

A animação de Abreu não se limita ao virtuosismo técnico, destacando-se também por seus traços duais. A jornada do personagem, com ações fundadas em fortes vínculos de causa e efeito, coexiste com rupturas para experimentação poética, sugerindo interfaces entre o clássico e o moderno. A peregrinação do campo à cidade, por sua vez, desdobra-se através de um regime narrativo duplo, que atribui traços particulares a cada um desses espaços. Tais dualidades estimulam uma busca conceitual, que ativará as interfaces entre cinema e cidade, bem como a migração de conceitos entre essas duas áreas de estudo. Neste sentido, em sintonia com Jean-Louis Comolli, pode-se definir 0 eixo campo-cidade, como o resultado de duplo gesto de "re-gard" (olhar, [reguardar]). Sua natureza seria aquela de um deslocamento ante ao visível, a partir de uma estetização que exterioriza significações e, por vezes, explicita gestos sociais latentes, internos aos habitantes (COMOLLI, 1997), que aqui serão indagados em diferentes níveis. Isso inclui o narrado e,

Junto a eventos como o Festival de Cinema de Anecy (2014), Festival de Cinema de Animação de Lisboa (2014) e o Annie Award (2016).

No Brasil, de acordo com Alê Abreu, o filme será lançado basicamente no circuito de arte do Circuito Espaço de Cinema, alcançando 35 mil espectadores, sem grandes destaques. Ao longo de sua carreira, porém, passará por diversos festivais e será vendido para inúmeros países. Quando da indicação como participante do Oscar, a equipe abriria uma campanha de financiamento coletivo, na plataforma Catarse, que arrecadaria 164 mil reais para a divulgação do filme nos EUA, colaborando com a GKids, distribuidora do filme em solo americano. Outro fator significativo do desempenho de 0 menino e o mundo, em outubro de 2016, será sua aparição como primeiro colocado da linha PRODAV 7 (Ancine), de suporte a obras brasileiras com bons resultados em festivais nacionais e internacionais. (REDAÇÃO, 10 out. 2016; GUIMARÃES, 14 jul. 2015) 
por outro lado, o discurso sobre o urbano, que é socialmente significado.

\section{0 campo e a cidade}

A história acompanha o trajeto de um garoto que, pequenino no campo, presencia a separação de seus pais e depois parte à cidade, em busca da figura paterna. Campo e cidade apresentam-se como personagens, que se relacionam a diferentes visões de mundo, ou regimes de enunciação.

0 campo será o local dos laços familiares, da memória e da natureza. Espaço das brincadeiras infantis, do convívio harmônico das diferenças, bem como de uma vibrante paleta de cores, estrategicamente associada à presença das culturas populares. 0 papel em branco, evocado como pano de fundo, é uma matéria virgem inventivamente apropriada, através do tracejar do lápis de cor e do giz de cera. A mesma operação, lúdica e inventiva, impulsiona as relações entre 0 visto e aquilo que extrapola as bordas do quadro. Ao longo da história, o espaço rural se associará à figura de uma grande ave colorida, síntese da liberdade e da pluralidade de culturas.

\section{Acompanhando a cisão da própria família} retirante, o menino se dirigirá à cidade, inicialmente apresentada como horizonte de cores densas e neons. A metrópole, por sua vez, se constituirá gradualmente, como local da organização e da simetria fabril, da exploração do operariado, da padronização cultural com tonalidades pop, da imposição da ordem por meio da força física e da estética militar. Nela, 0 branco de fundo será substituído pelo bege e por cores mais opacas, com traços coesos. A grafia tende à colagem e ao acúmulo de informações visuais. Nota-se um fora de campo que se coloca como continuidade serial, daquilo que já é visível dentro da imagem. Em termos de significado, tal espaço citadino se associará à figura de uma águia preta, cujas simetrias e poses remetem a algo de fáscio. Depois da tentativa urbana, com as diferentes tensões entre a racionalidade técnica citadina e as resistências da pluralidade rural, o personagem vivenciará um novo movimento de expulsão. 0 trajeto circular terminará, com 0 menino já crescido, de volta ao campo. Os laços familiares se reafirmarão, pela lembrança de dias felizes, com os pais e outras crianças do campo, estimulados por uma espécie de imaginação lúdica que acompanha todo o filme.

Contaminadas por uma visão de mundo infantil e transformadora, as tensões campo-cidade são os fios condutores da narrativa da animação aqui debatida. Dentro de suas particularidades, $O$ menino e o mundo é uma obra atenta aos trânsitos, aberta às interações de valores sob os ecos de uma sociedade em transformação socioeconômica.

As definições do campo e da cidade, bem como as relações entre eles estabelecidas, variam de acordo com os contextos teóricos e históricos envolvidos. Dentre a ampla bibliografia sobre 0 assunto, podem-se destacar alguns autores cuja abordagem é de interesse para 0 debate 
de $O$ menino e o mundo. A obra de Henri

Lefebvre, por exemplo, trata dos conceitos de rural, industrial e urbano como modos de organização do espaço. Trata-se de composições sociais que podem coexistir de maneira tensa, mas cuja sucessão resultaria de um projeto de transformação social. Para o sociólogo francês, o rural é marcado pela organização em comunidade, de homens que demonstram suas fraquezas ante à natureza, unidos através de propriedades e disciplinas coletivas (LEFEBVRE, 1978, p. 72). Já a cidade industrial resulta da concentração da população e dos meios de produção, paralelamente à existência da cidade como imagem que se interpõe entre homens e natureza. 0 urbano, por sua vez, seria um objeto virtual, que pressupõe a transformação do presente, com a realização das potencialidades de humanização já existentes na vida industrial.

Outra referência de interesse será o estudo das relações campo/cidade na literatura, realizado por Raymond Williams. Para o teórico inglês, tais espaços, bem como os significados a eles atribuídos, são realidades históricas em transformação. Em seu estudo A cidade e o campo na história e na literatura, há um mapeamento das representações de tais espaços, acompanhando as transformações sociais inglesas, decorrentes da revolução industrial na Inglaterra. Os matizes assumidos pelo campo e pela cidade serão variados. Numa operação que aqui nos interessa,
Williams identificará um grupo particular de obras, híbridas entre a literatura rural e a literatura urbana, que serão definidas como narrativas de fronteira (WILLIAMS, 1989, p. 356) atentas aos trânsitos entre tais espaços.

No caso do cinema brasileiro, o trajeto campocidade acompanhará as transformações do país ao longo dos séculos XX e XXI. Frente a isso, JeanClaude Bernardet (1980) propõe a possibilidade de mapear as tensões entre esses espaços, tomados como "expressões da evolução do capitalismo" no âmbito de "uma história ideológica do cinema brasileiro" (p. 150). Para ele, o campo-cidade é uma temática já presente na literatura e no teatro desde o século XIX e que, no cinema, a grosso modo, adquirirá três principais contornos ideológicos. Numa primeira vertente, identificável em Nhô Anastácio chegou de viagem (1908), sugere-se o interior como "preservação" e a cidade como "dissolução da moral"; ou seja, a visão dos avanços capitalistas urbanos como um ato de degeneração das relações familiares e da "ética tradicional" (p. 139). Numa segunda tendência, "filmes de exaltação urbana que simplesmente não querem saber do sertão" (p. 145), com a exaltação de um Brasil cosmopolita, caso de São Paulo, a symphonia da metrópole (1929). No contexto do cinema brasileiro moderno, haveria uma terceira variação, de especial interesse para pensar o menino e o mundo. Trata-se de uma crítica à cidade, construída como espaço sociologicamente negativo, que massacra e rejeita o migrante/ operário, mesclando-se, posteriormente, a 
uma visão pesada das sobreposições entre arcaico e moderno. Para os migrantes, a cidade permanecerá sedutora, mas esses serão tratados como bichos (BERNARDET, 1980, p. 148). Tal visão sociologicamente negativa se consolidará especialmente ao longo dos anos 1960-70, em documentários como Viramundo (1964-65) de Jose Sarno, ou Migrantes (1972) de João Batista de Andrade. Entre as ficções, Bernardet se referirá a A grande cidade (1966), de Carlos Diegues, e Zézero (1976) de Ozualdo Candeias. Apesar das grandes diferenças, tais filmes atentam para a dificuldade da inserção na cidade, os espaços marginais ou de exploração assumidos por alguns dos migrantes, as interações entre sedução e ingenuidade ante ao urbano, bem como a possibilidade de tomar o migrante enquanto classe social, entre o operariado e a mão de obra de reserva.

O menino e o mundo parece retomar o trajeto campo-cidade, sob os ecos da visão sociológica presente em tais obras. Enquanto construção ideológica, recoloca o migrante/operário seduzido, em suas dificuldades de inserção num cotidiano desumanizante. Entre as imagens finais, há enxertos de Iracema, uma transa amazônica (1974), denunciando as práticas predatórias da natureza pela civilização industrializada, e também, recolocando o desenvolvimento econômico excludente dos anos 1970 como uma das chaves de leitura. 0 filme de Alê Abreu, porém, apresenta tais tensões num novo contexto, no qual o inevitável extermínio do campo pela cidade é imbuído por alguma brecha utópica, a ser examinada. Em continuidade an enfoque proposto por Bernardet, na segunda parte desse artigo 0 menino e o mundo será aproximado a outras visões da cidade no período. Sob esse aspecto, podem-se identificar no filme coexistências, unindo as heranças de uma visão sociologicamente negativa e as possibilidades utópicas, no bojo dos debates sobre 0 direito à cidade em 2013.

Quanto à sua narrativa, a construção do campocidade se dará a partir do filtro da animação. As grafias particulares a cada um de tais espaços, com suas uniões e rupturas, parecem sobreviver sob um regime mais amplo, marcado pelas apropriações experimentais do cinema clássico e pelas constâncias de um vocabulário com ênfase às plasticidades. 0 menino que vai à cidade em busca do pai é um personagem forte, pautado por uma jornada com explícitos laços de causa e efeito. Pode-se destacar também a sua centralidade na construção do lugar do espectador no texto de $O$ menino e o mundo. Diversos dos planos corresponderão ao olhar do protagonista, incluindo táticas do cinema clássico, como a construção de planos-ponto- 
-de-vista. ${ }^{3}$ Diversas formas de enquadramento e montagem terão equivalentes em diálogo com o cinema clássico: planos gerais, closeups, zooms, travellings, transformações do campo/contracampo. No filme, tais recursos serão utilizados de modo particular, sugerindo sintonias entre o posicionamento do espectador e a visão de mundo do protagonista.

Em uma importante colaboração para a análise de animações, Jacques Aumont sugere que está em questão não apenas aquilo que é visto, mas sobretudo a forma como se vê, devendo-se aprofundar os procedimentos narrativos na qualidade de operações mentais (AUMONT, 1996, p. 180). No caso da animação aqui debatida, pode-se atentar para uma lógica narrativa com destaque à plasticidade, presente em sons, cores, traços e movimentos, que por vezes criam uma "pseudonarrativa" (PASOLINI, 1989, p. 154), que complementa de modo diacrônico a intriga principal. Assim podem ser pensados os diferentes grafismos e temperaturas de cores que variam entre o campo e a cidade. Em comum, um espaço fluido, em constante metamorfose, tendo o branco de fundo como espaço de liberdade a ser resgatado ou acuado. As falas dos personagens, articuladas em português invertido, terão uma presença tátil em sintonia com os grafismos visuais, significando a partir de vibrações e entonações. A configuração de uma lógica narrativa das plasticidades também terá desdobramentos sobre os raccords e construções espaciais. Na animação de Abreu, a sucessão de planos pode unir espaços bastante díspares, em termos de enquadramentos e proporções. Num ambiente plasticamente maleável, o protagonista desloca-se entre florestas, horizontes, jardins, morros e ruas, cada qual com suas regras de composição também cambiantes. A principal constante, neste caso, é uma espécie de geografia criativa, pautada pela presença gráfica e corporal do personagem, cuja função e atribuir continuidade a espaços diferentes e em constante mutação.

Como aqui debatido, o campo-cidade respeita uma dualidade de grafismos que, por sua vez, são integrados por um regime narrativo mais amplo, pautado pela plasticidade, que tenciona e complementa a intriga principal. As reincidências de tal regime ao longo de $O$ menino e o mundo, descritas aqui de maneira panorâmica, merecem uma análise mais detida, que será realizada no próximo tópico, a partir da noção de estilo indireto livre e de um exercício de segmentação.

\section{Estilo indireto livre: passagens lúdicas dentro de uma estrutura inspirada no musical}

0 exame do filme de Abreu permite identificar uma estrutura marcada por rupturas, na qual 0 estilo da animação é contaminado por uma visão de mundo infantil e transformadora. Aproximando-nos do cinema de poesia pasoliniano, são momentos de afirmação de um estilo indireto livre, nos quais 0 ato enunciativo é contaminado pela linguagem, ou visão de mundo, das personagens. 
Em termos de configuração narrativa, $O$ menino e o mundo parece dialogar com duas das facetas do estilo indireto livre. Isso inclui a apropriação do discurso de outrem, com contaminações entre as linguagens do narrador e do personagem, tal como sugerido por Bakhtin (2006), bem como a coexistência de estilos que, de acordo com Pasolini, assumiria, na Divina Comédia de Dante, a forma de um "tapete persa", com a fusão de almas e de mundos, a partir de uma poesia "que nasce da contaminação, do choque entre duas almas por vezes profundamente diferentes" (PASOLINI, 1989, p. 51).

A definição e 0 uso do estilo indireto livre, num contexto de trânsito da literatura ao cinema, serão realizados por Pasolini em seu L'expérience hérétique. 0 termo é originalmente pensado na literatura, para casos nos quais o narrador apropria-se da linguagem do personagem, gerando ambiguidades de enunciação, que serão tomadas por Pasolini como coexistências de estilos, classes ou estruturas sociais. Pelo estudo dos polos em jogo, em cada caso particular, seria possível identificar a transposição de tensões próprias ao contexto histórico de cada obra. Dadas as diferenças ante à literatura, no cinema estariam em pauta as ambiguidades de estilo. 0 fenômeno pode revelar-se em elementos como as cores, a montagem, 0 tratamento do tempo ou os movimentos de câmera, cujas modulações expressam a crise de personagens modernas ante ao mundo. Em tal cinema, que traz a potência dos sonhos, os traços estilísticos adquirem grande liberdade, constituindo-se como pseudonarrativas autônomas em sintonia com a neurose das personagens.

Em 0 menino e o mundo, o descompasso está no trajeto, realizado entre campo e cidade, mas também numa neurose infantil transformadora, vinculada à subjetividade do personagem em trânsito. Os devaneios, em si, constituem-se como eclosões do estilo indireto livre, numa estrutura que parece dialogar com o gênero musical. Identificados ao longo da história, eles envolvem modificações em termos de estilo da animação: acelerações do tempo, modificações na paleta de cores e no estilo dos traços, inserções sonoras, entre outros elementos. São pequenos clipes em meio à narrativa geral, postados em momentos de transição, especialmente quando as interações entre campo e cidade eclodem adversamente. Suas reiteradas aparições permitem pensar no filme como uma espécie de musical, contendo uma narrativa geral permeada por pequenas atrações, nas quais o regime narrativo sofre modificações, que incluem uma presença mais demarcada da música. São pequenos segmentos, nos quais há uma mudança na importância das relações entre imagem e som (CHION, 2003), apresentando-se não como enxertos de variedades, mas como números naturalmente associados ao roteiro e seus desdobramentos narrativos (SUTTON, 1981). Se no musical clássico identifica-se um dual focus (ALTMAN, 1978), cujas performances afirmam padrões duais de classificação social (homem/mulher, bem/mal), na animação de Abreu a existência 
dual parece projetar-se sobre o campo-cidade, com seus respectivos regimes narrativos e coexistências graduais.

Uma segmentação do filme, levando em conta o estopim de cada devaneio, indica a existência de 17 rupturas bem distribuídas ao longo da história. No final deste tópico, há uma tabela incluindo localização temporal, conteúdos, local diegético e regime narrativo correspondente a cada devaneio ${ }^{4}$. Como se percebe, tais passagens são contínuas e estruturais ao longo do filme, sendo oito delas na metade inicial e oito na metade final. A potência da ruptura, porém, será paulatinamente mais rarefeita, principalmente durante a segunda metade da história. A longo dos 85 minutos de filme, os devaneios se construirão a partir de dois regimes narrativos principais, associados respectivamente ao campo e à cidade, havendo também momentos de mesclas entre os dois regimes referidos:

\section{O campo: com o tracejo infantil; a paleta de cores vibrantes; a convivência harmônica de cores e texturas. 0 fundo branco,}

evocando a presença do papel sobre 0 qual se desenha. Neste contexto, a apropriação do fundo branco, bem como daquilo que está fora do enquadramento visível, corresponde a uma ação inventiva ${ }^{5}$.

\section{A cidade: local da organização e da} simetria fabril; ambiente marcado pela tendência à colagem e à reprodução serial de grafias industrializadas; nota-se 0 acúmulo de informações visuais; 0 fundo dominado pelo bege e por cores mais opacas; a tracejado mais coeso. Neste contexto, a apropriação do mundo tende a uma ação serial e de bricolagem. 0 fora de campo, espaço situado fora do enquadramento visível, coloca-se como mera continuidade serial daquilo que é visto na tela ${ }^{6}$

\section{Interações campo - cidade: diferentes} mesclas, entre as duas tendências anteriores, incluindo coexistências de traços narrativos, ou então, a construção de espaços intermediários (presenças da cidade no campo; presenças do campo na cidade). ${ }^{?}$

Ver Tabela 2.

Embora não seja o foco desse artigo, vale lembrar que a trilha sonora e musical do filme colabora de modo determinante para a diferenciação do campo-cidade. Isso se dá, sobretudo, pela variação dos timbres e ritmos na construção de ambiências sonoras. No caso do campo, os silêncios são cotejados com motivos lentos, brilhantes e quentes, tocados especialmente por instrumentos locais; predomínio da flauta barroca, com sua conotação infantil, que executa o assunto-tema do filme; a isso, somam-se os sons locais, as falas num dialeto incompreensível, e os suspiros do garoto.

Em termos sonoros, a cidade apresenta-se pela desumanização dos timbres, que se aproximam dos ritmos mecânicos das máquinas, ou dos passos do exercito pelas ruas. Na fábrica, são os sons das máquinas; na cidade a céu aberto, por vezes, uma massa de sons metálicos, rítmicos e indistintos. 
Tabela 1: Frames de 0 menino e o Mundo (2013), exemplificando os regimes narrativos identificados no filme.

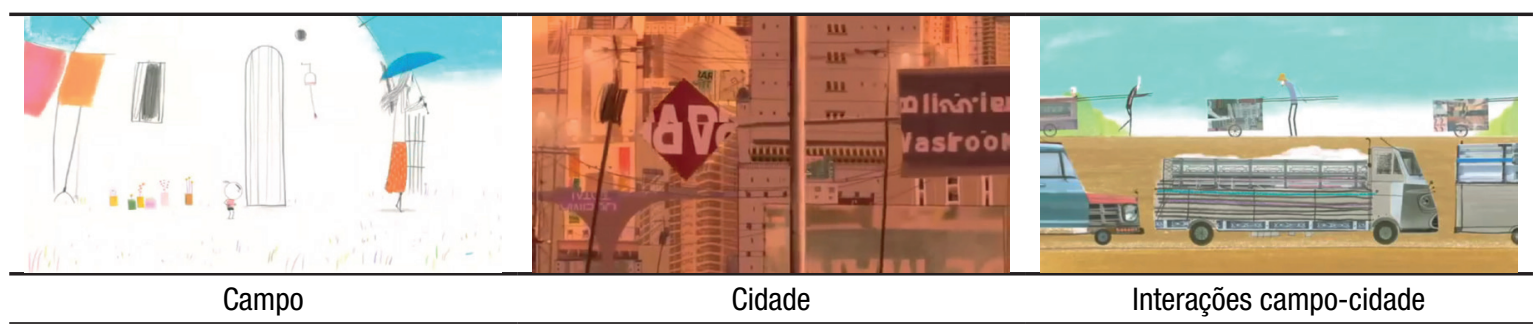

Fonte: 0 menino e 0 mundo (2013), de Alê Abreu. ${ }^{8}$

Com razoável intercalação entre si ao longo

do filme, tais regimes acompanham a jornada do protagonista, sugerindo o gradual trânsito, do campo à cidade e, depois, a volta à pureza campesina. Não há uma ancoragem necessária, entre 0 regime evocado e 0 espaço diegético no contexto do devaneio, possibilitando uma rica gama de interações. Para o respectivo estudo, faz-se necessária uma abordagem descritiva, com a identificação das oposições e interações de tais tendências, a partir de trechos selecionados ao longo de $O$ menino e o mundo.

Um dos primeiros dos devaneios, ainda no meio rural, é uma brincadeira lúdica com a inserção de formas seriais, reminiscências do urbano, no contexto da colheita do algodão. ${ }^{9} 0$ fundo musical confeccionado pelo Barbatuques ${ }^{10}$ é trazido ao primeiro plano. As células rítmicas e melódicas adequam-se ao tempo do trabalho agrário, a partir do timbre do violão, somado à resistência dos chocalhos, suspiros, vozes, entre outras sonoridades corporais. Apesar da força rítmica, quase industrial, as sonoridades associam-se a uma apropriação humana, do trabalhador com sua ação sobre a natureza. 0 tracejar a lápis e giz de cera convive, momentaneamente, com a colagem de grafias publicitárias. 0 branco de fundo, próprio à identidade rural do filme, une-se a temas seriais urbanos. Nota-se uma reverberação geral de traços rítmicos, entre a trilha sonora, a construção do campo de algodão com figuras geométricas, e os movimentos corporais dos trabalhadores

Quanto às construções sonoras, sugerirão uma união das tendências anteriores: em espaços intermediários, pela presença de ritmos sonoros mais padronizados e timbres de instrumentos industrializados; em espaços urbanos, pela ruptura da massa sonora citadina por fragmentos dos silêncios e pelo assunto-tema tocado em flauta barroca.

Disponível em: < https://www.youtube.com/watch?v=vrs5ScD_RxM>.Acesso em 30 out. 2017.

Devaneio 3 (Ver Tabela 2).

10 Grupo brasileiro de percussão corporal, cuja proposta é a composição de músicas a partir do batuque com o próprio corpo, resultando numa música rica em plasticidade sonora. 
aproximando-os de máquinas dançantes. Assim como nos devaneios seguintes, a diegese será parcialmente rompida, trazendo o olhar à superfície da tela, com seus jogos padronizados de movimentos e cores. 0 manusear onírico dos algodões é o início de uma linha temática que, paralelamente à trajetória do personagem entre campo e cidade, acompanhará a transformação da fibra em produto industrializado.

Neste primeiro momento, ao olhar do menino, a presença urbana é ainda uma novidade alegre, sob os rumores de uma já agressiva exploração do trabalhador agrário. Depois dessa passagem, ao seguir sua imaginação entre os pés de algodão, 0 garoto se deparará com novo devaneio ${ }^{11}$, agora evocando a liberdade e a fusão de culturas próprias ao universo rural. Neste caso, aproxima-se aqui de um regime enunciativo próprio ao campo. Rodeado pela imensidão branca, o garoto presenciará a chegada de um cortejo popular, em festa, com uma onda de tonalidades vivas e traços de lápis de cor. A plasticidade pictórica e dos movimentos tomará conta da superfície da tela, com um balé bidimensional que será retomado em passagens momentâneas da estadia pela cidade e no desfecho, sempre enquanto estilização extrema do regime narrativo associado à vida rural. Em tais passagens, quanto aos sons, nota-se uma marchinha musical, com um conjunto de vozes uníssonas, cujo significado mais forte é a união em torno de raízes culturais.

A chegada à cidade se completará depois de uma noite de tempestade, figurada por um dilúvio ${ }^{12}$, que é enfrentado pelo protagonista num carrinho de latão e madeira. Os movimentos de grandes ondas em azul esverdeado, a partir de traços ondulares contínuos, serão acompanhados pela ira dos violinos, formando um balé rítmico de movimentos gráficos e golpes sonoros.

Ultrapassado o umbral urbano de vias de rodagem, o menino se deparará com a indústria de tecidos, cuja apresentação incluirá um breve clipe. ${ }^{13} \mathrm{~A}$ composição dos corpos dos operários, na qualidade de extensões das máquinas em movimentos uníssonos, novamente partirá de associações entre ritmos visuais e sonoros. No contexto fabril, com o predomínio do fundo bege, a rede de trabalhadores coloca-se como instrumento de transformação industrial do algodão. A breve passagem anunciará traços gráficos e composicionais citadinos, unindo a tendência à colagem de figuras, a diminuição do calor das cores, bem como a simulação de travellings e panorâmicas, associando cidade e maior expressividade de movimentos racionais 
e retilíneos. Neste caso, a manifestação serial une movimentos dos corpos, máquinas e fluxos do algodão, desdobrando-se numa espécie de aniquilamento da criatividade humana. 0 s sons, mimetizando a mecânica fabril ou militar, confluem em ambiências metálicas e desumanas.

Durante a estadia urbana do personagem, novas configurações entre elementos do campo e da cidade serão presenciados, incluindo devaneios cada vez mais rarefeitos e com menor contraste ante ao regime narrativo predominante. Ao lado da composição de um urbano serial e fragmentar, haverá aqui e ali resistências, reviravoltas festivas e encontros da diversidade, designando uma afinidade geral pela cultura do campo, sob a sombra de uma urbanidade voraz.

Um dos momentos de resistência ocorrerá após a primeira noite de sono na cidade. Num morro periférico, o menino e seu amigo experimentarão o espaço urbano de maneira lúdica, descendo ladeiras de bicicleta, de maneira a flanar sobre os perigos físicos da metrópole ${ }^{14}$. A cidade opressiva se tornará uma montanha-russa. Além da aceleração da passagem entre os diferentes espaços, nota-se a multiplicação de cores, que culminará com uma visão caleidoscópica da cidade. Unem-se 0 estalar sonoro da bicicleta, a fragmentação visual da cidade e, por fim, 0 deleite geométrico de uma série de guarda-sóis na praia. A experiência se completará no devaneio seguinte ${ }^{15}$, no qual o menino interagirá com a cidade por meio de um caleidoscópio: experiência do urbano como interação deslumbrante de cores que, por sua vez, recolocará a vontade de volta ao campo. Tais momentos nos sugerem uma construção de si e da cidade mediada pelos reflexos. Não longe daquilo que Sylvia Cayubi denomina de autoimagem construída através do jogo de espelhos (NOVAES, 1993, p. 27-28), tem-se uma autorrepresentação dinâmica e multifacetada da criança, cujas transformações são paralelas às interações do campo-cidade e de seus valores conflitantes.

Ao longo do trajeto do garoto, as interações entre campo e cidade são explícitas, opondo regimes gráficos e significados, que sofrem uma mistura cada vez maior, porém com a manutenção de uma coexistência conflitante. Dentro deste quadro, merecem destaque os devaneios finais ${ }^{16}$, nos quais o menino, de volta à casa rural, vislumbra novo cortejo musical e depois sonha com formas caleidoscópicas. Construídas sob os vestígios de uma nostalgia familiar melodramática, sem deixar de lado alguma decadência, tais passagens causam estranheza ante a estrutura de coexistências conflitantes até então proposta. A memória aflorada

Devaneio 8 (Ver Tabela 2).

15 Devaneio 9 (Ver Tabela 2).

16 Devaneios 16 e 17 (Ver Tabela 2). 
na forma de um cortejo musical de crianças, cujos instrumentos expelem bolhas coloridas, seguida pelo sonho no colo materno, embalado por círculos em cores, ambos sob fundo branco, sugerem uma espécie de moral da história, na qual vale mais voltar as costas à cidade, substituindo-se as coexistências urbanas conflitivas por uma estranha pureza do rural, coroado como local da memória e dos afetos familiares.
A descrição retrospectiva dos devaneios, realizada aqui de modo seletivo, sugere uma estrutura com possíveis inspirações no musical clássico sob o viés sugerido por Rick Altman (1978), com sua divisão em dois núcleos de poder, que correspondem a padrões de organização narrativa e também social. Em 0 menino e o mundo, de modo particular, os momentos de ruptura não abrem espaço para shows, mas para a gradual

Tabela 2: Segmentação dos momentos de devaneio, ao longo de 0 menino e o mundo.

\begin{tabular}{|c|c|c|c|c|}
\hline & Início & Conteúdo & $\begin{array}{c}\text { Local } \\
\text { diegético }\end{array}$ & $\begin{array}{c}\text { Regime } \\
\text { narrativo }\end{array}$ \\
\hline 1 & $2 \min 44$ & Apresentação: menino brinca pela floresta e depois sobe às nuvens. & Campo & \\
\hline 2 & $13 \min 50$ & $\begin{array}{l}\text { Pesadelo noturno no trilho do trem: vegetação, trilho e flashes de memória em } \\
\text { cores neon, sob fundo negro. }\end{array}$ & Campo & \\
\hline 3 & $17 \min 00$ & Os trabalhadores rurais na coleta do algodão. & Campo & \\
\hline 4 & $22 \min 00$ & Cortejo musical evocando cultura popular em cores. & Campo & \\
\hline 5 & $26 \min 40$ & Dilúvio em direção à cidade. & Campo & \\
\hline 6 & $31 \min 28$ & Operários como extensão de máquinas na fábrica. & Cidade & \\
\hline 7 & $34 \min 58$ & Desfile militar, seguido por viagem de ônibus pela cidade. & Cidade & \\
\hline 8 & $40 \min 20$ & Descida do morro de bicicleta até a praia. & Cidade & \\
\hline 9 & $42 \min 45$ & $\begin{array}{l}\text { Música tocada em bicicleta instrumental, desdobrando em viagem } \\
\text { caleidoscópica pela cidade. }\end{array}$ & Cidade & \\
\hline 10 & $45 \min 55$ & Pesadelo no porto. & Cidade* & \\
\hline 11 & $47 \mathrm{~min} 03$ & $\begin{array}{l}\text { Navios são sugados pelos céus, por uma grande nave-cidade. Visões da } \\
\text { produção de tecidos a partir de imagens com simetrias em neon. }\end{array}$ & Cidade* & \\
\hline 12 & $51 \mathrm{~min} 00$ & Viagem pelas vitrines urbanas até estádio de futebol. & Cidade* & \\
\hline 13 & $52 \min 30$ & Festa popular no subúrbio, culminando com a ave coloria no céu. & Cidade $^{*}$ & \\
\hline 14 & $1 \mathrm{~h} 01 \min 15$ & Confronto entre ave negra da cidade e ave colorida rural. A segunda é aniquilada. & Cidade $^{\star}$ & \\
\hline 15 & 1h05min37 & $\begin{array}{l}\text { Pesadelo: mundo urbano avança sobre o rural. Página branca é queimada; } \\
\text { imagens documentais de devastações da natureza }\end{array}$ & Campo & \\
\hline 16 & $1 \mathrm{~h} 11 \mathrm{~min} 12$ & Crianças em cortejo musical no campo & Campo & \\
\hline 17 & $1 \mathrm{~h} 12 \mathrm{~min} 27$ & Devaneio final com imagens caleidoscópicas sobre fundo branco. & Campo & \\
\hline
\end{tabular}

Regime narrativo:

campo
cidade
interações campo/cidade
* rupturas mais amenas, com limites menos definidos para o começo ou fim do devaneio. 
contaminação da enunciação pelos êxtases do personagem, sob os quais também subjaz um desejo de paz rural e a solução dos conflitos representados pela cidade. Talvez possamos pensar numa cidade da transformação, que inclui a opressão e 0 encontro, as transformações festivas sob a sombra do avanço industrial, ou ainda, a gradual dissolução do modelo do musical a partir do borrar das fronteiras. Por fim, um estilo indireto livre no qual o campo-cidade é construído sob um viés lúdico e transformador, que leva em conta os contrastes entre opressão e liberdade, mas culmina com 0 saudosismo ante à natureza e 0 coroamento melodramático da vida rural.

\section{Interpretações a partir do contexto: versões e apropriações do direito à cidade}

\section{O menino e o mundo dialoga com um desejo}

de cidade, (tomado como reapropriação do espaço, de si e das linguagens sobre o urbano) que parece ter paralelos no contexto de 2013. Nas interfaces entre o rural e 0 citadino reconstruídos por Abreu, como debatido, identificam-se momentos de ruptura, nos quais as oposições são tensionadas e por vezes superadas a partir de coexistências lúdicas. 0s temas e o percurso, por um lado, apontam para a existência dual de tais espaços. 0 ato enunciativo do filme, por sua vez, propõe momentos de superação utópica dos mesmos. Do ponto de vista interpretativo, levando em conta factíveis diferenças, talvez se possa aproximar 0 gesto artístico de $O$ menino e o mundo em relação à noção lefebvriana de urbano, operação escrita e teórica que pressupõe uma implosão-explosão (LEFEBVRE, 1999) com vistas à realização de utopias fragmentares.

Em seu $O$ direito à cidade, Henri Lefebvre propõe o urbano como um projeto utópico, de realização de possibilidades de humanização represadas, que implicaria na saturação e na explosão das oposições entre 0 urbano e 0 industrial, paralelamente a uma mistura temporal, entre o passado e o possível. A operação teórica envolve o embate, complexo e contraditório, entre dois termos particulares. Por um lado, o urbano: a cidade tomada como obra, ou valor de uso, desdobrando-se na apropriação das ruas, praças e monumentos, a partir do encontro e da festa. Por outro lado, o industrial: a cidade como produto, ou valor de troca, pensado sob a racionalidade do dinheiro e do mercado (LEFEBVRE, 1991, p.11-12). Com base nas análises realizadas no tópico anterior, é possível identificar, em 0 menino e o mundo, a reivindicação por uma sociedade urbana, no sentido lefebvriano. Isso inclui, especialmente, as tensões entre obra e produto, respectivamente identificadas no eixo campo-cidade e suas coexistências.

De maneira não gratuita, no contexto social de produção do filme de Abreu, identifica-se um conjunto de discursos, escritos e audiovisuais, que retomam a noção de direito à cidade, à luz das assim chamadas jornadas de junho de 2013. O menino e o mundo (2013), vale assim destacar, em nenhum momento refere-se explicitamente 
às jornadas. A retomada de tais discursos, porém, possibilita aproximações conceituais, bem como a identificação de singularidades. Quantos aos eventos, trata-se de movimentos de reivindicação, ocorridos no Brasil, inicialmente concentrados em torno das classes médias e da questão da mobilidade urbana, mas cujas pautas posteriormente tornam-se bastante dispersas, somando-se outras classes sociais às manifestações (SINGER, 2013) ${ }^{17}$.

Para retomar o referido contexto, podem-se examinar as presenças da noção de direito à cidade em três frentes, divididas entre 0 discurso do MPL - Movimento Passe Livre, a Geografia Humana e imagens realizadas por grupos de ativistas ao longo do período, vistas como construções ideológicas ${ }^{18}$. Nestes três casos, tratamos de discursos que revisitam a noção de direito à cidade, e que serão aqui retomados de modo bastante pontual, com 0 objetivo de identificar as proximidades e particularidades. Em consonância, $O$ menino e o mundo propõe uma crítica ao capitalismo do período, tendo por base a reapropriação da cidade e de seus usos. De modo particular, o filme recoloca as tensões campo-cidade como parte do debate, o que se desdobra em possíveis ambiguidades, logo à frente debatidas, quanto à defesa da natureza e à coexistência festiva das diferenças.

Fugindo de uma historicização de 2013, um dos principais discursos que acompanham a tomada das ruas é aquele do próprio $M P L$ - Movimento Passe Livre. Reivindicando uma atuação política descentralizada, a partir da ação ramificada entre espaços de ensino e as ruas em diferentes cidades do Brasil, o MPL desponta como um dos agentes deflagradores das ondas reivindicatórias de 2013, inicialmente centradas no debate da mobilidade urbana e da abolição das tarifas de transporte público. Em seus discursos sobre si, a apropriação da cidade aparecerá como instrumento de guerra, de forma a afrontar e colocar em pauta o desentrave dos espaços. Entre suas reivindicações (MPL, 2013, p. 13-18), a luta pela cidade e a ocupação do espaço urbano colocam-se como armas de barganha, para a

Para o cientista político André Singer, os eventos de junho de 2013 teriam em sua base as classes médias tradicionais somadas a um novo proletariado, constituído ao longo do governo do PT, que padecia de condições ainda precárias de emprego. Os acontecimentos podem ser divididos em três fases. Na primeira, circunscrita a São Paulo, frações da classe média organizam-se em torno de um objetivo específico, a redução das tarifas do transporte público, seguindo um modelo adotado pelo MPL - Movimento Passe Livre. Numa segunda fase, aflorada após grande repressão policial, o movimento alcançaria seu auge, com a entrada espontânea de outras frações da sociedade, o pipocar em outras capitais e a diluição das demandas. Na terceira etapa, concentrada no final do mês, o movimento se fragmentaria em mobilizações parciais. Apesar dos tremores produzidos, com 0 aflorar de milhões de manifestantes às ruas das principais capitais do país, os mesmos não teriam questionado o "travejamento fundamental da ordem", as "relações de classe e propriedade", tampouco "as regras do jogo político”. (2013, p. 24).

18 Vale lembrar que, para Eni Orlandi, a ideologia pode ser percebida como "o processo de produção de um imaginário, isto é, a produção de uma interpretação particular que apareceria no entanto como interpretação necessária, e que atribui sentidos [...] às palavras num contexto histórico dado" (ORLANDI, 2007, p. 96.). 
reinclusão da população nas decisões sobre a construção do urbano. Desta maneira, enquanto gesto de apropriação da cidade, o MPL defende os bloqueios para a criação de novos fluxos, paralelamente à consciência da cidade como lócus de reivindicação.

No mesmo contexto, o geógrafo David Harvey retoma a noção de direito à cidade, explicitando sua importância conceitual junto aos eventos de 2013: "0 direito à cidade não pode ser concebido como um simples direito de visita ou um retorno às cidades tradicionais. Ao contrário, ele pode apenas ser formulado como um renovado e transformado direito à vida urbana" (HARVEY, 2013, p. 18). Entre as referências usadas por Harvey para definir tal direito, estão Robert Park (1967), para quem a mudança da cidade implica a mudança de si mesmo, e Henri Lefebvre, cuja teoria aponta para a necessidade de ação política e transformadora, onde as diferenças e conflitos são aflorados para a consolidação de uma sociedade urbana (LEFEBVRE, 1999). Trata-se de um direito ativo de fazer a cidade diferente, por meio de uma ação que envolve uma imaginação utópica, bem como a possibilidade da mudança, a partir do vislumbre da diferença efetivamente existente. ${ }^{19}$ Na proposta de Harvey, inspirado por outros teóricos do urbano, o direito à cidade será uma ação de criação de "espaços urbanos comuns [e de] uma esfera pública de participação democrática” (HARVEY, 2013, p. 33), de modo a retomar os espaços de encontro e da diferença, perdidos no contexto do capitalismo avançado, com suas cidades globais pautadas pelo desenvolvimento humano e espacial desigual.

No campo do audiovisual, entre uma imensa gama de agentes e posicionamentos possíveis, os vídeos realizados por certos grupos de ativistas parecem revisitar a questão do direito à cidade. É 0 caso dos materiais da Ação Direta de Vídeo Popular, incluindo vídeos de agit-prop que constroem uma cidade dos embates entre a multidão pacífica e a opressão policial. Divulgados no início de junho de 2013 e realizados no bojo das manifestações, vídeos como " $1^{0}$ ato contra 0 aumento das tarifas do transporte público", "30 ato SP luta contra 0 aumento da passagem 2013" e "4 $4^{0}$ ato contra 0 aumento das tarifas 2013 "20 são marcados pela denúncia, a afronta à polícia e, sobretudo, pela união entre a violência e o desejo de transformação pelo confronto. São pequenas parábolas urbanas do embate entre manifestantes pacíficos e polícia violenta, que se desdobram em confrontos corporais. 0 direito à cidade, neste

19 "0 direito à cidade não pode ser concebido como simples direito de visita ou retorno às cidades tradicionais. Só pode ser formulado como direito à vida urbana transformada, renovada. [...] Pouco importa que o tecido urbano concentre em si o campo e aquilo que sobrevive da vida camponesa, conquanto que 'o urbano', lugar de encontro, [...] encontre sua [...] realização prático-sensível." (LEFEBVRE, 1991, p .117.) [grifo nosso] 
caso, é inevitavelmente mediado pela ação física e conflitante tendo o espaço urbano como palco. Na plataforma youtube do mesmo grupo, há vídeos relacionados a embates urbanos mais amplos, em torno do direito à moradia em São Paulo, que implicam na ocupação e resistência ante às forças policiais e municipais ${ }^{21}$, ou na reivindicação jurídica pela manutenção de espaços ociosos reabitados ${ }^{22}$. Aqui, o direito à cidade equivale ao potencial de resistência, em termos de grupos humanos organizados e a presença do cinegrafista como parte constituinte de tal ação.

No mesmo contexto, 0 menino e o mundo (2013) retoma um sentimento de cidade particular, imbuído por uma utopia não destituída de ambiguidades. Primeiramente, há uma retomada da cidade como espaço sociologicamente negativo, massacrante, mas com pontos de escape para a criação do novo. Ao contrário de outras construções do 2013 aqui referidas, centradas em ações de resistência citadinas, em 0 menino e o mundo, o direito à cidade se associa ao direito ao campo, bem como à nostalgia de uma possível retomada de sociabilidades rurais. Narrativamente, a volta do personagem ao campo e seu reencontro com a ruralidade familiar colaboram para um final feliz, que poderia ser melhor palatável ao espectador acostumado à narrativa do cinema clássico. Num mundo em que as causas ecológicas têm cada vez mais destaque, o happy end de $O$ menino e o mundo legitima-se como politicamente correto, com brechas a ambiguidades. Apesar da face de engajamento ecológico, vale lembrar que Lefebvre atentará para as possibilidades retrógadas do direito à natureza. Quando tomada como "gueto dos lazeres", "lugar esperado do gozo", ou local daqueles que voltam as costas à problemática urbana, a natureza seria neutralizada e mercantilizada; nesse sentido, "0 direito à natureza contraria 0 direito à cidade sem conseguir eludi-lo" (LEFEBVRE, 1999, p. 117).

Outra das ambiguidades, possibilitadas pelo filme em seu contexto, refere-se à construção da pluralidade cultural, a qual acompanha o filme como um todo, apresentando-se especialmente pelas recorrências de cortejos populares festivos, com suas tensões variadas e, no desfecho, sob um viés apaziguador. Tais passagens festivas, com suas profusões de cores, tracejares e extratos culturais, ecoam aquilo que seria uma retomada do "sentido da obra" e "da apropriação (do tempo, do espaço, do corpo, do desejo)" (LEFEBVRE, 1999, p. 140), por um homem consciente de $\mathrm{si}^{23}$.

21 Ver "Comunidade do Moinho resiste!", "Moinho Ocupa - Parte l" e "Chamada 50. Ato Favela do Moinho". Disponíveis em: <https://www.youtube.com/channel/UCKNRqngGzpbmg20SXfl1XeA>. Acesso em 05 set. 2016.

22 Ver “Ocupação Tupã”, disponível em: <https://www.youtube.com/watch?v=XowVTtxG42w>. Acesso em 17 set. 2016.

23 Para Lefebvre, o urbano, sob o domínio do valor de uso, pressupõe: "os encontros, confrontos das diferenças, conhecimentos e reconhecimentos recíprocos" (LEFEBVRE, 1999, p. 22) 
A possibilidade de recriação do novo apresenta-se também na composição musical de tais extratos: originalmente um cortejo de vozes e tambores marcantes, explicitando a própria fusão musical, entre 0 samba e 0 frevo. Tais estilos trazem em si, geneticamente, os trânsitos culturais entre campo e cidade. Quanto ao tipo de identidade sugerida, em tais passagens pode-se potencializar uma identidade móvel, resultante de cotejos diversos, entre 0 citadino e 0 rural, em sintonia com aquilo que Stuart Hall define como uma "celebração móvel" (HALL, 2005, p. 13); ou seja, transformada continuamente, de acordo com câmbios dos meios e das formas de representação. Mas, se nos devaneios citadinos de 0 menino e o mundo 0 caleidoscópio se afirma como figura emblemática, por outro lado, a potência das raízes rurais se impõe de modo predominante no desfecho, com um cortejo de crianças que ambienta o happy end. Tudo isso precede os créditos finais, que trazem nova fusão do campo-cidade, com o grito de reivindicação urbana, do rap "Aos olhos de uma criança”, do DJ Emicida, que se dispõe sobre a profusão de cores de grafias rurais-infantis. ${ }^{24}$

Ao mesmo tempo, no contexto histórico de o menino e o mundo, as festas e convivências das diferenças seriam apropriadas, de modo inverso, por alguns gestores urbanos. Cidades como Rio de Janeiro e São Paulo passavam por processos que envolviam a requalificação urbana, bem como a transformação da imagem da cidade no bojo de grandes eventos esportivos. Em tais ações, a convivência das diferenças seria desejável e associada à imagem de grandes cidades mundiais, nas quais a cultura seria usada como estratégia para a valorização de espaços urbanos. Em Condição Pós-Moderna, Harvey atentará para 0 ecletismo como estratégia pós-moderna de revitalização de espaços deteriorados, chegando ao exemplo da Baltimore City Fair, feira anual dos anos 1980, na cidade de Baltimore, na qual as manifestações de minorias seriam transformadas em espetáculos para atração de multidões (HARVEY, 2008, p. 90). Otília Arantes (2012) associará o tema a intervenções para revitalização urbana, com investimentos em polos e festas culturais, como as viradas culturais (2005-2018) de São Paulo. Tomando-se o filme de Abreu em suas sintonias com a pluralidade cultural e a referida gestão estratégica urbana, 0 gesto artístico correspondente pode cercar-se de ambiguidades: internamente, a pluralidade e 0 encontro afirmam-se como obra; entre as possíveis apropriações contextuais, por outro lado, nota-se seu flerte como produto. Em seu conjunto, assim, o filme de Abreu incorpora 0 direito à cidade não

Algum tipo de ambiguidade, por sua vez, pode ser atribuída ao DJ Emicida, responsável pela música tema do filme: um rapper cuja radicalidade aos poucos é amortecida pelo mercado no qual este se insere; um artista cujos clipes iniciais promoviam uma ocupação insurgente do centro urbano pela cultura da periferia, mas que atualmente adere ao circuito cult das viradas culturais paulistanas - eventos que unem valor de uso e valor de troca; reapropriação do espaço a partir da diferença, mas também, reconstrução das imagens de uma cidade com o objetivo de valorizá-la. 
sem ambiguidades, seja sob o viés do direito à natureza, seja quanto à questão da coexistência das diferenças, levando-se em conta construções internas e possibilidades contextuais de leitura.

\section{Considerações finais}

Dadas as tensões aqui elencadas, num contexto de transformações sociais ainda não consolidadas, o filme parece aproximar-se daquilo que Pasolini denomina de uma obra instável "que vive a inquietude motriz, a necessidade de metamorfose, de uma estrutura que quer ser uma outra estrutura" (1989, p. 17). Ao fim do percurso, a instabilidade de 0 menino e o mundo revela sua sintonia ante a um contexto social também de instabilidades. 0 movimento geral da narrativa, situada entre as coexistências antagônicas e o apaziguar melodramático, por sua vez, ecoa com voracidade a incorporação das culturas divergentes contra e pelo capitalismo do período.

Resta, porém, sondar a natureza da utopia presente no filme de Alê Abreu. Se, em sua origem etimológica, o termo utopia pode associar a uma situação de não lugar, no livro Utopia, de Thomas More, apresenta-se como tipo de literatura, na qual as relações entre o real e o possível são marcadas pela plausibilidade. É aquilo que Lacroix denominará como possibilidade de existência que, ao contrário de uma simples fantasmagoria, trata-se de "uma nova realidade cuja essência aparece diretamente na existência" (LACROIX, 1996, p. 65). Ou seja, uma construção que toma dados concretos do presente como lastros para o possível. Em seu Direito à cidade, Lefebvre trata da ideia de "transdução", uma operação intelectual que consiste na construção de um objeto possível a partir de observações empíricas, que incidem sobre a própria realidade presente. Tal operação associa-se a uma "utopia experimental", que inclui a busca por espaços propícios à festa e à felicidade (LEFEBVRE, 1991, p. 108). 0 termo será retomado por Mannheim (1972), no contexto do estudo das ideologias, tomando-se as utopias como imagens de desejo que se opõem à ideologia dominante, na qualidade de apontamentos para mudanças no presente. Diante desse panorama, 0 menino e o mundo aproxima-se ambiguamente daquilo que poderia ser um gesto utópico. Enquanto forma, os devaneios identificados ao longo da narrativa inicialmente colocam-se como rupturas com tendência ao fantástico, mas que, ao longo do filme, têm suas fronteiras borradas, adquirindo algo de utópico, numa operação que, de fato, parece unir as esferas do presente e do possível. Uma hipotética superação da dualidade campocidade é cada vez mais presente, nesta narrativa que não esconde o desejo do encontro e da realização de humanizações represadas num presente de confrontos. Por outro lado, o tipo de ideologia visitada, ao culminar por um desejo de volta ao campo e à ordem familiar perdida, não deixa de ter tons conservadores. Se Bakhtin [1929] e, posteriormente, Pasolini [1972] defendem o estudo da linguagem, como espaço privilegiado para a identificação de confrontos sociais, 
tomando-se 0 estilo indireto livre sobretudo como coexistência de estilos, sob esse viés o menino e o mundo adquire densidade. Sua retomada da dicotomia campo-cidade, em seus confrontos e dissoluções, a partir de um gesto de utopia ambígua, dá-se num contexto particular: período este em que a web, bem como a reinvenção das relações entre massas urbanas e política, propõem novas polaridades e apropriações do urbano, a serem examinadas.

\section{Referências}

ALTMAN, Rick. The american film musical: paradigmatic structure and mediatory function. Wide Angle, n.2, p. 10-17, jan. 1978.

ARANTES, Otília. Barcelona e Berlim: duas imagens estratégicas. São Paulo: Annablume, 2012. AUMONT, Jacques. Lindustrie du plastique Goldorak des studios Toei. In: À quoi pensent les films? Paris: Seguier, 1996. p. 174-195.

; MARIE, Michel. A análise do filme. Lisboa: Texto \& Grafia, 2013.

BAKHTIN, Mikhail. Marxismo e filosofia da linguagem. São Paulo: Hucitec, 2006. [1929] BERNARDET, Jean-Claude. A cidade e o campo, notas iniciais sobre a relação entre a cidade e 0 campo no cinema brasileiro. In: ANDRADE, Rudá et al. Cinema brasileiro: 8 estudos. Rio de Janeiro: MEC - Embrafilme - Funarte, 1980. p. 139-150. Os jovens paulistas. In: $\mathbf{0}$ desafio do cinema. Rio de Janeiro: Zahar, 1985, p. 65-91. BRANIGAN, Edward. 0 plano-ponto-de-vista. In: RAMOS, Fernão Pessoa (Org.) Teoria
Contemporânea do Cinema, volume II. São Paulo: Editora Senac São Paulo, 2005. p. 251-275.

CHION, Michel. La comédie musicale. Paris: Cahiers Du Cinema/ Scérén-CNDP, 2003.

COMOLLI, Jean-Louis. A Cidade Filmada. Cadernos de Antropologia e Imagem, Rio de Janeiro, UERJ/ Núcleo de Antropologia e Imagem, ano 3, n. 4, 1997. GUIMARÃES, Thayz. 0 menino e o mundo é vendido para 80 países. FILME B, 14 jul. 2015. Disponível em: < http://www.filmeb.com.br/noticias/nacional/0menino-e-0-mundo-e-vendido-para-80-paises $>$. Acesso em 29 abr. 2018.

HALL, Stuart. A identidade cultural na pósmodernidade. Rio de Janeiro: DP\&A, 2005.

HARVEY, David. Condição pós-moderna. São Paulo: Ed. Loyola, 2008. A liberdade da cidade. In. MARICATO, H. (Org.) Cidades rebeldes. São Paulo: Boitempo, 2013. LACROIX, J. A Utopia. Rio de Janeiro: Zahar, 1996.

LEFEBVRE, Henri. De lo rural a lo urbano. Barcelona: Edicións 62, 1978. . 0 direito à cidade. São Paulo: Ed. Moraes, 1991. A revolução urbana. Belo Horizonte: Ed. UFMG, 1999.

MANNHEIM, K. Ideologia e utopia. Rio de Janeiro: Zahar, 1972.

MORE, Thomas. A Utopia. São Paulo: Nova Cultural, 1997. [1516]

MPL. Não começou em Salvador, nem vai terminar em São Paulo. In. MARICATO, H. (Org.) Cidades rebeldes. São Paulo: Boitempo, 2013, p. 13-18.

NOVAES, Sylvia Caiuby. Jogo de Espelhos. São Paulo: Edusp, 1993. 
ORLANDI, Eni. As formas do silêncio. Campinas, SP:

Editora da Unicamp, 2007.

PARK, Robert. On Social Control and Collective

Behavior. Chicago: Chicago University Press, 1967.

PASOLINI, Pier Paolo. L' expérience hérétique. Paris:

Ramsay, 1989. [1972]

REDAÇÃO. Ancine: sai resultado da linha de desempenho. FILME B, 10 out. 2016. Disponível em:

$<$ http://www.filmeb.com.br/noticias/distribuicaoproducao/ancine-sai-resultado-da-linha-dedesempenho > . Acesso em 29 abr. 2018.

SINGER, André. Brasil, junho 2013. Novos Estudos, São Paulo, n.97, p.23-40, nov. 2013.

SUTTON, Martin. Paterns of mining in the musical. In. ALTMAN, R. (Org.) Genre, the musical - a reader. London/Boston: Routledge, 1981.

WILLIAMS, Raymond. De novo a fronteira. In: 0 campo e a cidade: na história e na literatura. São Paulo: Companhia das Letras, 1989. p. 356-364. 
0 menino e o mundo (2013) by Alê Abreu: city and countryside, free indirect discourse and the right to the city

\section{Abstract}

The purpose is to analyze the animation 0 menino e 0 mundo (2013) by Alê Abreu, taking into account thematic, narrative and interpretive aspects. This includes, respectively: a) questioning the peculiarities relating to the representation of the countryside and the city (Bernardet, 1980); b) identifying a narrative structure with playful moments of free indirect style appearance (Pasolini, 1989), where the enunciation regimes are altered; $c$ ) examining the artistic gesture of $O$ menino e o mundo, with its traces of transforming utopia, not unambiguously, inserting it among other discourses that take up the right to the city (Harvey, 2013; Lefebvre, 1999), under the echoes of 2013 journeys.

\section{Keywords}

Animation cinema. City and countryside. Free indirect discourse.

\section{0 menino e o mundo (2013)} de Alê Abreu: campo y ciudad, discurso indirecto libre y el derecho a la ciudad.

\section{Resumen}

El objetivo es analizar la animación 0 menino e o mundo (2013), de Alê Abreu, teniendo en cuenta aspectos temáticos, narrativos y interpretativos. Se trata, respectivamente, de: a) cuestionar las particularidades en cuanto a la representación del campo y de la ciudad (BERNARDET, 1980); b) identificar una estructura narrativa con momentos lúdicos, de eclosión del estilo indirecto libre (PASOLINI, 1989), en los cuales los regímenes de enunciación experimentan modificaciones; c) examinar el gesto artístico de 0 menino e o mundo, con sus vestigios de utopía transformadora, no sin ambigüedades, insertándolo entre otros discursos que retoman el derecho a la ciudad (HARVEY, 2013, LEFEBVRE, 1999), bajo los ecos de las jornadas de 2013.

\section{Palabras-clave}

Cine de animación. El campo y la ciudad. Discurso indirecto libre. 


\section{Expediente}

A revista E-Compós é a publicação científica em formato eletrônico da Associação Nacional dos Programas de Pós-Graduação em Comunicação (Compós). Lançada em 2004, tem como principal finalidade difundir a produção acadêmica de pesquisadores da área de Comunicação, inseridos em instituições do Brasil e do exterior.

\section{E-COMPÓS I www.e-compos.org.br I E-ISSN 1808-2599}

Revista da Associação Nacional dos Programas de Pós-Graduação em Comunicação. Brasília, v.21, n.3, set/dez. 2018. A identificação das edições, a partir de 2008, passa a ser volume anual com três números. Indexada por Latindex I www.latindex.unam.mx

\section{CONSELHO EDITORIAL}

Ada Cristina Machado Silveira, Universidade Federal de Santa Maria, Brasi Alda Cristina Silva da Costa, Universidade Federal do Pará, Brasil Alfredo Luiz Paes de Oliveira Suppia, Universidade Estadual de Campinas, Brasil Ana Carolina Rocha Pessôa Temer, Universidade Federal de Goiás, Brasil Ana Regina Barros Rego Leal, Universidade Federal do Piauí, Brasil André Luiz Martins Lemos, Universidade Federal da Bahia, Brasil Angela Cristina Salgueiro Marques, Universidade Federal de Minas Gerais, Brasil Ângela Freire Prysthon, Universidade Federal de Pernambuco, Brasil Anna Cristina Pertierra, Western Sidney University, Austrália Antonio Carlos Hohlfeldt, Pontifícia Universidade Católica do Rio Grande do Sul, Brasi Arthur Ituassu, Pontifícia Universidade Católica do Rio de Janeiro, Brasil Bruno Campanella, Universidade Federal Fluminense, Brasil Bushra Hameedur Rahman, University of the Punjab, Paquistão, Paquistão Cárlida Emerim, Universidade Federal de Santa Catarina, Brasil Carlos Del Valle Rojas, Universidad de La Frontera, Chile Carlos Eduardo Franciscato, Universidade Federal de Sergipe, Brasil Cláudio Novaes Pinto Coelho, Faculdade Cásper Líbero, Brasil Danilo Rothberg, Universidade Estadual Paulista, Brasil Denise Tavares, Universidade Federal Fluminense, Brasil Diógenes Lycarião, Universidade Federal do Ceará, Brasil Dóris Martínez Vizcarrondo, Universidad de Puerto Rico Mayagüez, Porto Rico Eduardo Vicente, Universidade de São Paulo, Brasil

Eliza Bachega Casadei, Escola Superior de Propaganda e Marketing - SP, Brasil Elvira Gomes dos Reis Freitas, Universidade de Cabo Verde, Cabo Verde Eneus Trindade, Universidade de São Paulo, Brasil Erick Felinto de Oliveira, Universidade do Estado do Rio de Janeiro, Brasil Erick Torrico, Universidad Andina Simón Bolívar, Bolívia, Bolívia Erly Vieira Júnior, Universidade Federal do Espírito Santo, Brasil Fabio La Rocca, Université Paul-Valéry Montpellier 3, França Fernando Firmino da Silva, Universidade Federal da Paraíba, Brasil Francisco de Assis, FIAM-FAAM Centro Universitário, Brasil Francisco Elinaldo Teixeira, Universidade Estadual de Campinas, Brasil Francisco Gilson Rebouças Pôrto Junior, Universidade Federal do Tocantins, Brasil Francisco Sierra Caballero, CIESPAL, Equador Frederico de Mello Brandão Tavares, Universidade Federal de Ouro Preto, Brasil Gabriela Reinaldo, Universidade Federal do Ceará, Brasil Germán Rey Beltrán, Universidad Nacional de Colombia, Colômbia Gilson Vieira Monteiro, Universidade Federal do Sul da Bahia, Brasil Gustavo Daudt Fischer, Universidade do Vale do Rio dos Sinos, Brasil Gustavo Hernández Díaz, Universidad Central de Venezuela, Venezuela Heidi Figueroa Sarriera, Universidad de Puerto Rico, Porto Rico Ignacio Aguaded, Universidad Huelva, Espanha Inesita Soares de Araújo, FIOCRUZ, Brasil Itania Maria Mota Gomes, Universidade Federal da Bahia, Brasil Jiani Adriana Bonin, Universidade do Vale do Rio dos Sinos, Brasi João Carlos Ferreira Correia, Universidade da Beira Interior, Portugal Jonathan Cohen, University of Haifa, Israel José Afonso da Silva Junior, Universidade Federal de Pernambuco, Brasil José Luiz Aidar Prado, Pontifícia Universidade Católica de São Paulo, Brasil Josette Maria Monzani, Universidade Federal de São Carlos, Brasil Juçara Gorski Brittes, Universidade Federal de Ouro Preto, Brasil Julián Durazo Hermann, Université du Québec à Montreal, Canadá Juliana Freire Gutmann, Universidade Federal da Bahia, Brasil
Karla Yolanda Covarrubias, Universidad de Colima, México Laura Loguercio Cánepa, Universidade Anhembi Morumbi, Brasil Leonel Azevedo de Aguiar, Pontifícia Universidade Católica do Rio de Janeiro, Brasil Leticia Cantarela Matheus, Universidade do Estado do Rio de Janeiro, Brasil Ling Chen, Hong Kong Baptist University, China Luciana Coutinho Souza, Universidade de Sorocaba, Brasil Marcel Vieira Barreto Silva, Universidade Federal da Paraíba, Brasil Marcia Tondato, Escola Superior de Propaganda e Marketing, Brasil Márcio Souza Gonçalves, Universidade do Estado do Rio de Janeiro, Brasil Maria Ataide Malcher, Universidade Federal do Pará, Brasil Maria das Graças Pinto Coelho, Universidade Federal do Rio Grande do Norte, Brasi Maria Elena Hernández Ramirez, Universidad de Guadalajara, México Maria Elisabete Antonioli, Escola Superior de Propaganda e Marketing - SP, Brasil Maria Teresa Quiroz, Universidad de Lima, Peru Marialva Carlos Barbosa, Universidade Federal do Rio de Janeiro, Brasil Marina Poggi, Universidad Nacional de Quilmes, Argentina Marli Santos, Faculdade Cásper Líbero, Brasil Mateus Yuri Passos, Universidade Metodista de São Paulo, Brasil Mauricio Mario Monteiro, Universidade Anhembi Morumbi, Brasil, Brasil Mayka Castellano, Universidade Federal Fluminense, Brasil Mirta Varela, Universidad de Buenos Aires, Argentina

Mozahir Salomão Bruck, Pontifícia Universidade Católica de Minas Gerais, Brasil Neyla Graciela Pardo Abril, Universidad Nacional de Colombia, Colômbia Nísia Martins Rosario, Universidade Federal do Rio Grande do Sul, Brasil Olga Guedes Bailey, Nottingham Trent University, Reino Unido Paolo Demuru, Universidade Paulista, Brasil

Paolo Peverini, LUISS, Itália

Paško Bilić, Institute for Development and International Relations, Croácia Paula Melani Rocha, Universidade Estadual de Ponta Grossa, Brasil Potiguara Mendes Silveira Jr, Universidade Federal de Juiz de Fora, Brasil Rafael Cardoso Sampaio, Universidade Federal do Paraná, Brasil Rafael Tassi Teixeira, Universidade Tuiuti do Paraná, Brasil Regiane Lucas de Oliveira Garcêz, Universidade Federal de Minas Gerais, Brasil Regiane Regina Ribeiro, Universidade Federal do Paraná, Brasil Renata Pitombo Cidreira, Universidade Federal do Recôncavo da Bahia, Brasil Renato Essenfelder, Escola Superior de Propaganda e Marketing, Brasil Roberto Elísio dos Santos, Universidade Municipal de São Caetano do Sul, Brasil Robson Borges Dias, Universidade Católica de Brasília (UCB), Brasil Rodolfo Rorato Londero, Universidade Estadual de Londrina, Brasil Rosario Sanchéz Vilela, Universidad Católica del Uruguay, Uruguai Roseli Figaro, Universidade de São Paulo, Brasil Saima Saeed, Jamia Millia Islamia, India Sara Brandellero, Leyden University, Holanda Simone Maria Andrade Pereira de Sá, Universidade Federal Fluminense, Brasil Sônia Caldas Pessoa, Universidade Federal de Minas Gerais, Brasil Sun Sun Lim, Singapore University of Technology and Design, Singapura Tatiana Oliveira Siciliano, Pontifícia Universidade Católica do Rio de Janeiro, Brasil Thaïs de Mendonça Jorge, Universidade de Brasília, Brasil Valquiria Michela John, Universidade Federal do Paraná, Brasil Vicky Mayer, Tulane University, Estados Unidos da América do Norte Yamile Haber Guerra, Universidad de Oriente, Cuba 


\section{CONSELHO CIENTÍFICO}

Cristiane Freitas Gutfreind, Pontifícia Universidade Católica do Rio Grande do Sul, Brasil I Eduardo Antonio de Jesus, Universidade Federal de Minas Gerais, Brasil I Eduardo Morettin, Universidade de São Paulo, Brasil I Irene de Araújo Machado, Universidade de São Paulo, Brasil

\section{COMISSÃO EDITORIAL}

Igor Pinto Sacramento, Universidade Federal do Rio de Janeiro, Brasil I Kelly Cristina de Souza Prudencio, Universidade Federal do Paraná, Brasil | Miriam de Souza Rossini, Universidade Federal do Rio Grande do Sul, Brasil

\section{EDITORES ASSOCIADOS}

Rafael Grohmann, Faculdade Cásper Líbero, Brasil I Thaiane Moreira de Oliveira, Universidade Federal Fluminense, Brasil

\section{CONSULTORES AD HOC}

Ada Machado, Universidade Federal de Santa Maria, Brasil | Ana Carolina Escosteguy, Universidade Federal de Santa Maria, Brasil | Andrea França, Pontifícia Universidade Católica do Rio de Janeiro, Brasil | Ariane Holzbach, Universidade Federal Fluminense, Brasil | Benjamim Picado, Birkbeck College, Inglattera | Bruno Souza Leal, Universidade Federal de Minas Gerais, Brasil I Eduardo Morettin, Universidade de São Paulo, Brasil I Felipe Trotta, Universidade Federal Fluminense, Brasil | Francisco Rüdiger, Pontifícia Universidade Católica do Rio Grande do Sul, Brasil | Gislene da Silva, Universidade Federal de Santa Catarina, Brasil | Inês Vitorino, Universidade Federal do Ceará, Brasil I Isaltina Gomes, Universidade Federal de Pernambuco, Brasil I Jairo Ferreira, Universidade do Vale do Rio dos Sinos, Brasil I Karina Janz, Universidade Estadual de Ponta Grossa, Brasil | Kati Caetano, Universidade Tuiuti do Paraná, Brasil | Lilian França, Universidade Federal do Sergipe, Brasil | Liziane Guazina, Universidade de Brasília, Brasil I Márcio de Vasconcellos Serelle, Pontifícia Universidade Católica de Minas Gerais, Brasil I Marta Maia, Universidade Federal de Ouro Preto, Brasil I Maurício de Bragança, Universidade Federal Fluminense, Brasil I Nina Velasco e Cruz, Universidade Federal de Pernambuco, Brasil | Norval Baitello Jr., Pontifícia Universidade Católica de São Paulo, Brasil | Pedro Guimarães, Universidade do Estado do Rio de Janeiro, Brasil | Priscilla Perazzo, Universidade Municipal de São Caetano do Sul, Brasil I Sofia Zanforlin, International Association of Media and Communication Research, Estados Unidos I Talitha Ferraz, Escola Superior de Propaganda e Marketing, Brasil I Tattiana Teixeira, Universidade Federal de Santa Catarina, Brasil I Victa de Carvalho Pereira da Silva, Universidade Federal do Rio de Janeiro, Brasil

\section{EQUIPE DE EDITORAÇÃO}

ASSISTENTE EDITORIAL Marcio Telles | REVISÃO DE TEXTOS Fátima Áli | EDITORAÇÃO ELETRÔNICA Roka Estúdio

\section{COMPÓS I www.compos.org.br}

Associação Nacional dos Programas de Pós-Graduação em Comunicação

Presidente

Marco Roxo

Programa de Pós-Graduação em Comunicação - UFF

marcos-roxo@uol.com.br

Vice-Presidente

Isaltina Gomes

Programa de Pós-Graduação em Comunicação - UFPE

isaltina@gmail.com

Secretária-Geral

Gisela Castro

Programa de Pós-Graduação em Comunicação

e Práticas de Consumo - ESPM

castro.gisela@gmail.com

CONTATO I revistaecompos@gmail.com 